\title{
Oxidation of Earth's big mantle wedge by recycled Ca-carbonate
}

\author{
RENBIAO TAO, YINGWEI FEI
}

Carnegie Institution for Science, 5251 Broad

Branch Road, NW, Washington DC 20015, USA

Recent observations of $\mathrm{Fe}^{3+}$-rich majorite inclusions from websterite xenolith and diamond raise a question on the formation mechanism of these $\mathrm{Fe}^{3+}$ rich majoritic garnets in deep Earth's mantle. In this study, we experimentally verified a possible redox reaction between carbonate and $\mathrm{Fe}^{2+}$-rich mantle mineral at high-pressure and high-temperature condition relevant to subduction zone in deep Earth's mantle. Experimental results show that both $\mathrm{Fe}^{2+}$ garnet and $\mathrm{Fe}^{2+}$ olivine can be oxidized to $\left(\mathrm{Ca}, \mathrm{Fe}^{3+}\right)$ rich garnets with $\mathrm{Fe}^{3+} / \sum \mathrm{Fe}$ up to $\sim 1$ by Ca-carbonates under deep mantle conditions, whereas carbonate is reduced to graphite/diamond through the redox reaction. $\mathrm{Fe}^{3+}$ contents in synthetic majoritic garnets are pressure-dependent. The higher pressure, the more $\mathrm{Fe}^{3+}$ contents in the synthetic garnets. This redox mechanism can be used to interpret the relation between $\mathrm{Fe}^{3+}$ rich garnet inclusions in diamond from deep Earth' mantle. Our experimental result is a direct link for the formation of diamond and the oxidation of big mantle wedge at highpressure and high-temperature conditions. Considering the molar ratio of oxidant and reductant in the redox reaction: $\mathrm{C}^{4+}$ (Ca-carbonate) + $4 \mathrm{Fe}^{2+}{ }_{\text {(mantle rock })}=4 \mathrm{Fe}^{3+}$ (majoritic garnet) $+\mathrm{C}_{\text {(graphite/diamond), }}$ we propose that recycled $\mathrm{Ca}$-carbonate is the most efficient metasomatic agent of oxidization of Earth's big mantle wedge through geological time. 